\title{
Exploration on the Stakeholders' Cooperation Mechanism of the Postgraduate Studies Scholarship System
}

\author{
Yao-bin SHI \\ College of Resource and Environmental Engineering \\ Wuhan University of Science and Technology \\ Wuhan, P.R.China \\ E-mail: drift_alone@163.com \\ Hong-jie ZHANG \\ College of Resource and Environmental Engineering \\ Wuhan University of Science and Technology \\ Wuhan, P.R.China \\ E-mail: zhanghongjie304@126.com
}

\author{
Yi-cheng YE \\ College of Resource and Environmental Engineering \\ Wuhan University of Science and Technology \\ Wuhan, P.R.China \\ E-mail: yyc60@126.com
}

\begin{abstract}
Based on the stakeholder theory, this paper explores multi-dimensional relation and difference characteristics of postgraduate studies scholarship stakeholders. It provides a new perspective and method for the research and practice of the postgraduate studies scholarship system by discusses the main factors and propose appropriate countermeasures in stakeholders' cooperation mechanism. Research shows that the scholarship system is the collaborative mechanism of government, university, teachers, students, family and society. And it has the characteristics of the " scholarship system - stakeholder" multi direction cyclic cooperative mode. Some suggestions are offered on how to improve the postgraduate studies scholarship system. Firstly, consciousness and the ability of the resources allocation need to be further improved, and supply and demand of mechanism need to be optimized continuous. Secondly, stakeholder relationships need to be integrated and built fully, by consummate the mechanism of system design, system evaluation, practice management and Information feedback. Thirdly, in order to process of ascension type control management ability and competition advantage for graduate students, innovation incentive oriented mechanism need to be optimized continuous.
\end{abstract}

Keywords: postgraduate studies scholarship; stakeholders, cooperation mechanism; comprehensive educational reforms

\section{INTRODUCTION}

In 2013, the ministry of finance, national development and reform commission, the ministry of education has released "Opinions on improving the investment mechanism of Graduate Education", graduate education formally entered the stage of comprehensive reform in China. On July 29, 2013, "postgraduate studies scholarship management interim measures" had issued, it clearly put forward the postgraduate studies scholarship is set up for "encourage graduate students to work hard, with great concentration of scientific research, innovation, positive enterprising, and better support for postgraduate complete their studies smoothly in the case of the graduate education practices the comprehensive charge system. It have shown that postgraduate studies scholarship is an important part of the postgraduate award funding system, and is the biggest special funds postgraduate assistantship in Chinese graduate education. More importantly, postgraduate studies scholarship is a basic scholarship to improve the education comprehensive reform, bring about a reform in graduate student "public education" to "comprehensive charge education"[1,2].

The implementation of the postgraduate studies scholarship system brings the influence of different level to the various stakeholders. The scholarship of stakeholders, is refers to the practice of the system in the certain education specific investment (or contribution), expect a certain interest, and assumes the risk of the individual (or group). The stakeholders' corresponding behavior can influence the realization of the system of scholarship, or under the influence of scholarship system.

Practice shows that, multi stakeholder groups in graduate school scholarship system [3], such as object subject, management organization, and evaluation group and benefit object, are influence each other. The system is faced with very different from other assistance and scholarship system in distinct environment and mode selection. Therefore, it is necessary to clarify the various properties and characteristics of stakeholders [4, 5], and further explore the synergy mechanism of different stakeholders in postgraduate studies scholarship system practice.

In this paper, multidimensional relation and difference features of postgraduate studies scholarship system was discussed, and coordination model of the scholarship system was structured based on stakeholder theory. It provides a new perspective and method for postgraduate studies scholarship system research and practice.

\section{STAKEHOLDERS OF POSTGRADUATE STUDIES SCHOLARSHIP SYSTEM}

Postgraduate studies scholarship is develop from "graduate basic scholarship" (2009, "notice of further postgraduate cultivation mechanism reform pilot work") to "graduate scholarship" (2013, “postgraduate studies scholarship management interim measures"). It is an 
important part of the China's education input mechanism, and also a significant components of the graduate assistance and scholarship system (as in [2]). Inevitably, there exists a corresponding contact and influence in practice of postgraduate studies scholarship stakeholders, with the reason of stakeholders and their interests will be affected at multiple factors, multiple target structure of system composition, distribution standard, and distribution proportion.

Stakeholder theory was put forward in 1963(SRI International), and widely used in the business communities of strategic management, corporate governance, corporate social responsibility and business ethics management. The theoretical research and empirical test of stakeholder theory has achieved great progress, its social influence have been rapidly expanding [5]. In recent years, the stakeholder theory is introduced in the field of higher education, become important research visual angle and analysis framework of the management of university organization [6].

\section{A. Stakeholders definition}

The stakeholders of postgraduate studies scholarship refer to those with close interest relations and academic scholarship community. Because of the stakeholders' core concept of 'to what extent or range is related' is no unified view, graduate school scholarship system stakeholders can be defined on higher education stakeholders' definition. In other words, any organization or individual, who related to the scholarship system, can be seen as its stakeholders.

Therefore, the stakeholders of postgraduate studies scholarship include the government sector, university, teachers, students, family and society.

\section{B. Stakeholders structure}

Various stakeholders provide important resources, or contribution to the postgraduate studies scholarship system. In the actual transaction, every stakeholder want to their own interests are met. The various stakeholders of interest groups can be seen as a coordinated interaction of cooperative system (Figure 1). To consider the rights and interests of each stakeholder group argues, it is necessary to put stakeholder groups in the postgraduate scholarship practice system under the background of graduate education comprehensive reform.

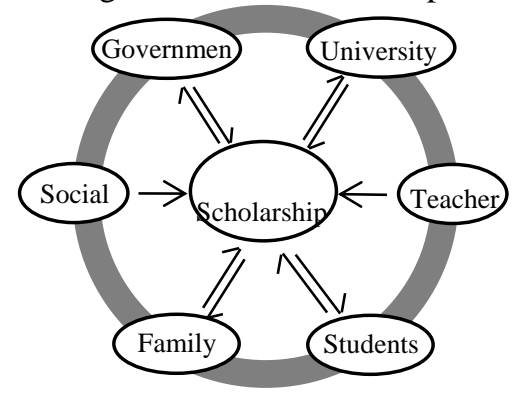

Figure 1. The stakeholder relationship of postgraduate studies scholarship

- The government policy guidance is the key in clear scholarship grants, target and development direction, and also the key of supervision and reviewing system practice.
As a special education investment, postgraduate studies scholarship has the remarkable 'the policy' attribute characteristics. In the construction of the scholarship system, education financial department special subsidies (investment) is the main source of funding, accounts for over $60 \%$ of the total amount of the scholarship. Besides, postgraduate studies scholarship has strict procedures of the capital audit, investment and budges. Macro level, the system has realized the postgraduate education from the era of 'public education' to 'self-expense education', broken the original system of public expense postgraduate education of China. To some extent, these systems guarantee the fairness of education and to achieve the optimal allocation of social resources. Under the background of postgraduate education comprehensive reform, the key points of government level in the system of postgraduate studies scholarship are guarantee the function of "basic scholarship", effective implementation of education cost-sharing, incentive postgraduate scientific research innovation, improving the quality of postgraduate education.

- University is the basis platform of postgraduate studies scholarship construction and practice, and the only practice base of the scholarship system implement and optimize.

Unquestionable, it is a new innovation oriented mechanism that was constructed under the postgraduate studies scholarship system construction, which is different from another postgraduate scholarships' mechanism, such as state grants, national scholarship, school scholarship, and society scholarship in China. On the one hand, tuition revenue, research funds and administrative budget will be necessary to replenish education investment while supplementing postgraduate studies scholarship funding sources. Such as Central South University set up the national and school postgraduate studies scholarship at the same time, $60.04 \%$ and $39.96 \%$ of revenues in class 2014 , respectively, in 2015 (as in [2]). On the other hand, universities play a core role in the scholarship practice relationship obviously. System efficiency and function of scholarship are affected or indirectly affected of student enrollment, evaluation rules, management organization and audit mechanism. Universities in the construction of postgraduate grant system, especially the postgraduate studies scholarship evaluation and examination system building, has made the positive exploration and practice, and has many years of practice.

- Teachers is main administrator of design, practice and optimize in postgraduate studies scholarship, but also the key practitioners guarantee the grass-roots practice effectiveness, fairness and scientific.

Teachers play three key roles in the postgraduate studies scholarship system. Firstly, the administrator of higher education are compiling, perfecting and elaborating the scholarship system, constantly constructing and enriching the connotation of institutional practice. Second, postgraduate advisor play role of the first person responsible, strengthen the system's ties with students, and participate in system design and optimization. Thirdly, effective postgraduate counselors' governance offers the system the competence sense and coordination to execute and innovate within a given set of system constraints. In recent years, various universities of 
China had designed the rules of the system with strengthen the function of the first responsible person of postgraduate advisor. It makes clear a regulation, "the scholarship is not granted when the tutor thought that the student failed to fulfill his responsibilities". It also had been clear about the counselor' specific job responsibilities of scope, supervisory authority and management content. Then it effectively guarantees the fairness and effectiveness of the postgraduate studies scholarship system. The management of universities is a comprehensive system to the budget review and funds management of the academic scholarship practice.

\section{SYNERGETIC MECHANISM OF POSTGRADUATE} STUDIES SCHOLARSHIP UNDER THE VIEW OF STAKEHOLDERS

The construction and improvement of the postgraduate studies scholarship system is the work of the stakeholders. Although the starting point, the reference department and the demand of each stakeholder are different, the ultimate goal is to ensure that postgraduates successfully complete their studies and improve the quality of education. In scholarship system, the relationships between the stakeholders and the scholarship system, and the various stakeholders are systematically regarded as interactions. Based on the promotion of integrity, continuity and effectiveness of students' process development, aiming to achieve the "objective development" of postgraduate. The formation of coordination mechanisms contributes to properly handle the postgraduate studies scholarship stakeholders' relationships.

To clarify the coordination mechanism, it is necessary to classify and analyze the "interest attributes" and "related degree" of the stakeholders based on the cooperative attributes of the various stakeholders of the system, and selects the core stakeholder.
Therefore, according to Mitchell's attribute analysis method, defining the attributes of the postgraduate studies scholarship system stakeholders as follow:

(1) Legitimacy. It shows whether a group is given power for the scholarship system systematically and morally (claim or be claimed), which includes the "essence" of the scholarship, and "value" related to security and incentive.

(2) Power. It shows whether a group has the status, ability and corresponding means to influence the development of scholarship system, system implementation and system management.

(3) Urgency. It shows whether the requirements of a group can lead to concern of postgraduate scholarship system decision makers.

At the same time, the four decisive factors that affect the influence of stakeholders on the scholarship mechanism should be considered. The social attribute and social conditions of stakeholders, namely, the objective factors of the subjective composition, the system design and the management supervision, and, the objective conditions of the basic form of postgraduate education, the characteristics of postgraduate' attributes and social function needs. Stakeholders have the power, that is, the subjective ability in the capital investment, system design, standard evaluation and quantitative assessment. Stakeholders' determination to achieve certain goals, that the main body of the system seek the benefits for the system practice, functional feedback and functional play, and the means and method used by stakeholders while using their power. Analyzing the attributes of the six types of stakeholders related to the scholarship system, and determining the corresponding attributes between stakeholders, as shown in table 1.

TABLE I. POSTGRADUATE STUDIES SCHOLARSHIP’ ATTRIBUTES BETWEEN THE VARIOUS STAKEHOLDERS

\begin{tabular}{|c|c|c|c|c|c|c|}
\hline stakeholders & Government & University & Teacher & Student & Family & Society \\
\hline Government & - & deterministic & expected & deterministic & deterministic & deterministic \\
\hline University & deterministic & - & expected & deterministic & deterministic & expected \\
\hline Teacher & expected & expected & - & deterministic & potential & potential \\
\hline Student & deterministic & expected & expected & - & deterministic & expected \\
\hline Family & deterministic & expected & expected & deterministic & - & expected \\
\hline Society & expected & expected & expected & deterministic & deterministic & - \\
\hline
\end{tabular}

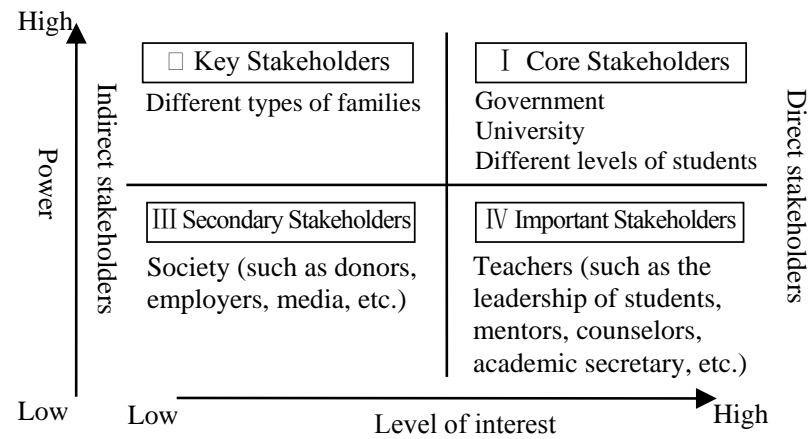

Figure 2. Orientation of Stakeholders in the Cooperative Mechanism of Postgraduate Studies Scholarship
As result, the stakeholders of postgraduate studies scholarship are divided into core stakeholders, key stakeholders, important stakeholders and secondary stakeholders based on the impact and interest of the various stakeholders on the scholarship system (figure 2).

In terms of the level of interest, focus should be given to core stakeholders (government, university and postgraduate) as key players, performers and beneficiaries, and key stakeholders (Teachers). The practice and improvement of the system are directly related to it and should meet the corresponding functional requirements. Major stakeholders (households) and secondary stakeholders (societies) are relatively passive. And only under certain conditions, such as 
difficulties in family conditions and increased social contributions, will the practice of the scholarship system must be affected.

In terms of the power, government, university, postgraduate and family are the high-impact objects in the system's implementation and practice, because their behaviors are directly involved to and affecting the realization of the objectives of the scholarship system. The corresponding teachers and society's influence on the system is limited, and the urgency and benefits of the system construction and improvement are lower.

Other stakeholders, in addition to family and social contributions, have promoted the demand for social responsibility behavior in postgraduate tuition reform systems. On the one hand, in the opinion of stakeholders, that is, in the opinion of scholarships and beneficiaries, the response of the various stakeholders to the postgraduate studies scholarship itself and its utility shows that the scholarships play an important role in communication (contact) between postgraduate tuition reform system social responsibility behaviors and stakeholders. On the other hand, stakeholders respond to social responsibility of the postgraduate tuition reform systems through personal interests and value recognition in the process of accepting the practice and improvement of the system, so that postgraduate tuition reform system society responsible behavior gets the proper feedback. Governments, universities, teachers and society demand a solid professional knowledge, academic level and innovation to improve the practical requirements through the academic scholarship system, but also more willing to assume a systematic, co-ordinated scholarship system to achieve the improvement of the social responsibility and the sense of value of the stakeholders. Correspondingly, postgraduates also need a clear incentive-oriented and process development quantitative assessment mechanism. And the family needs to "sharing" social welfare in the stage from "public postgraduate students" to "charge postgraduate students", also hopes to get higher education responsibility through the postgraduate scholarship system.

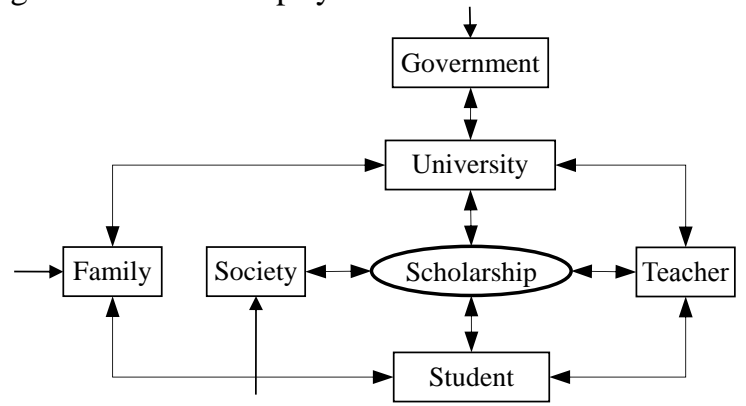

Figure 3. "Six in one" coordination mechanism model of postgraduate studies scholarship

Therefore, the scholarship stakeholders are put into a systematic, which form the "Postgraduate Scholarship System - Stakeholders" multi-way cooperative model, that is, "six in one" coordination mechanism model of postgraduate studies scholarship, as shown in figure 3 .

\section{SUGGESTIONS}

Since the reform and opening up, the scale of postgraduate education has been gradually expanded, the training ability has been continuously strengthened, the mechanism of investment has been gradually improved, and a development road which conforms to China's national conditions has been formed preliminarily. However, compared with the new situation and requirements of the educational reform and development, there are still some problems, such as the contradiction of cultivation fund between supply and demand, the unsoundness of cost sharing mechanism and the imperfect of reward policy system needs to be solved. In the course of the practice of postgraduate studies scholarship, it is necessary to further improve the reform system of tuition charge and improve the investment mechanism of postgraduate education so as to optimize the allocation of educational resources, and finally improve the cultivation quality of postgraduate education and promote the sustained and development.

\section{A. Further improve the awareness and ability of resource allocation, improve the coordination between supply and demand.}

The connotation of the configuration of postgraduate studies scholarship resources (human, material, force), the most important issue is the coordination of supply and demand. To ensure the effectiveness, fairness, responsibility and efficacy of the practice of scholarship system, it is necessary to have clear strategic positioning of postgraduate studies scholarship and others scholarships, and to grasp the development direction and quality of the system practice, then, to handle the input and output of various stakeholders properly. Government need to be in accordance with national economic construction and social development needs to protect the fairness of resource allocation of "marginal disciplines (professional)" (The profession which the number of enrollment students or in school are less) and "popular discipline (professional)" which be on the basis of original support and encouragement "Tilt to the basic disciplines and countries in urgent need of disciplines (professional, direction)", and to subordinate the education resources of provincial and municipal university coordinately, integrate the university resources and markets, and balance the regional development and overall layout.

B. Integrate and construct the relation of stakeholders, improve the feedback mechanism of system design system evaluation - practice management - information fully.

University is at the core station of postgraduate studies scholarship practice, which is the basic platform of the practice of academic scholarships. What kind of measures and programs of universities to construct the relationship are the decisive significance to the practical performance of the scholarships. The only way to maintain and continuously improve the work effort and the quality of scholarships is to respect and coordinate the interests of the various stakeholders under the context of the reform of postgraduate tuition charge. In the context of postgraduate comprehensive charge, 
postgraduate studies scholarship have been given a lot of new missions, and universities in their practice are facing a dilemma. Universities should not abandon the fundamental foothold of the traditional scholarships of "award merit", and avoid the "outstanding" of "speculation" in the "speculation" in the integration and construction of scholarship scholarships, nor can bear excessive social responsibility. So that make the postgraduate studies scholarship "fission" for academic grants and academic research special reward, leading to ignore the scholarships of the essential characteristics and historical mission. At the same time, it is suggested that universities should regard the sustainable development of school as the target, and follow the principles and rules of postgraduate education and training in dealing with the relation between stakeholders. It not only need to consider their own interests, but also need to pay attention to other stakeholders, and regard the interests of stakeholders as the constraints and support conditions of a university to pursue their own interests, and actively strive for policy support, excellent students and capital investment, to achieve multi-win in the coordination of interests between stakeholders

\section{Through continuous optimization, innovation, incentive and guidance mechanism, the process control management ability and postgraduate competition advantages can be improved.}

The construction and optimization of the innovation incentive orientation mechanism is the core element and the central link of postgraduate studies scholarship practice, including the system structure (content), assessment mechanism and innovation orientation, which determines the trend of the innovation of educational investment mechanism, the orientation of postgraduate education and training and the direction of the development of students' comprehensive quality ability. The relevant problems in the reform of the overall tuition system for postgraduates can be externalized. Therefore, to adapt to the impact of changes in the macroeconomic environment, the government and the university should further understand and reflect the needs of stakeholders at the macro level. It is recommended to absorb other stakeholders outside of the government and the
University of Evaluation Committee. At the same time, reexamining the three ministries on deepening the reform of graduate education opinions (2013), combined with the requirements of "graduate academic interest, knowledge structure, ability level, individualized training plan", revise and improve the system from the service demand, improve the quality of "point of view and further improve the academic scholarship incentive innovation orientation consciousness. Furthermore, strengthen the management functions of the first responsible person and graduate tutor, based on overall postgraduate award help system, able to identify and properly handle the relations between stakeholders, especially to meet the unique needs of individual or group assessment mechanism to form the different levels, quality and conditions of postgraduate.

\section{ACKNOWLEDGEMENT}

This research was financially supported by "Program on Graduate's Ideological and Political Education, Hubei, P.R.China (No.2017ZX10)", "Project on Graduate education reform research of Wuhan University of Science and Technology, P.R.China(No. Yjg201724), and "Provincial Higher Education Research Project, Hubei, P.R.China (NO. 2014235)".

\section{REFERENCES}

[1] Z. J, "Countermeasures for the Challenges, Problems of the Financial Support System for Graduate Students based on the Overall Charging System", Academic Degrees and Graduate Education, No. 5, Mar. 2015 , pp. 63-68, doi: 10.16750/j.adge.2015.03.017.

[2] Y. B. SHI, Y. C. YE, and Y. YANG, "Issues Related to Graduate Scholarship Assessment and Its Dynamic Adjustment”, Journal of graduate Education, No. 4, Apr. 2016, pp.16-21.

[3] R. E. Freeman, K. Martin, and B. Parmar, "Stakeholder Capitalism", Journal of Business Ethics, vol. 74, No. 4, Sep. 2007, pp. 303-314.

[4] G. XU, H. B. MA, "Reflections on the issues in graduate academic Scholarship Granting", Academic Degrees and Graduate Education, No. 12, Dec. 2015, pp. 27-32.

[5] C. D. HU, and Y. M. TIAN, "A few Theoretical Issues Concerning Stakeholders for Higher Education”, China Higher Education Research, No. 6, Jun. 2010, pp. 15-19.

[6] Z. L. CHENG, Z. H. HU, and W. B. LIU, "Stakeholder Theory Based Performance Management in Universities", Journal of Hunan University(Social Sciences), vol. 25, No. 2, Feb. 2011, pp. 63-67. 